\title{
Association of CKIP-1 P21A polymorphism with risk of chronic heart failure in a Chinese population
}

\author{
Mu-Peng Li ${ }^{1,2}$, Yan-Jiao Zhang ${ }^{1,2}$, Xiao-Lei Hu ${ }^{1,2}$, Ji-Peng Zhou ${ }^{1,2}$, Yong-Long Yang ${ }^{3}$, \\ Li-Ming Peng ${ }^{4}$, Hong $\mathrm{Qi}^{4}$, Tian-Lun Yang ${ }^{4}$ and Xiao-Ping Chen ${ }^{1,2}$ \\ ${ }^{1}$ Department of Clinical Pharmacology, Xiangya Hospital, Central South University, Changsha 410008, Hunan, P. R. China \\ ${ }^{2}$ Institute of Clinical Pharmacology, Central South University, Hunan Key Laboratory of Pharmacogenetics, Changsha 410078, \\ Hunan, P. R. China \\ ${ }^{3}$ Haikou People's Hospital and Affiliated Haikou Hospital of Xiangya Medical School, Central South University, Haikou 570311, \\ Hainan, P. R. China \\ ${ }^{4}$ Department of Cardiovascular Medicine, Xiangya Hospital, Central South University, Changsha 410008, Hunan, P. R. China \\ Correspondence to: Xiao-Ping Chen, email: chenxp74@hotmail.com \\ Keywords: CKIP-1, polymorphism, cardiac hypertrophy, chronic heart failure, prognosis
}

Received: December 08, $2016 \quad$ Accepted: February 28, $2017 \quad$ Published: March 28, 2017

Copyright: Li et al. This is an open-access article distributed under the terms of the Creative Commons Attribution License (CC-BY), which permits unrestricted use, distribution, and reproduction in any medium, provided the original author and source are credited.

\section{ABSTRACT}

Pathological cardiac hypertrophy is an independent risk factor for chronic heart failure. Casein kinase-2 interacting protein-1 (CKIP-1) can inhibit pathological cardiac hypertrophy. Therefore, we investigated whether CKIP-1 nonsynonymous polymorphism rs2306235 (Pro21Ala) contributes to risk and prognosis of chronic heart failure in a Chinese population.A total of 923 adult patients with chronic heart failure and 1020 age- and gender-matched healthy controls were recruited. CKIP-1 rs2306235 polymorphism was genotyped using PCR-restriction fragment length polymorphism. Additional follow-up data for $\mathbf{1 4 0}$ chronic heart failure patients was evaluated. The rs2306235 G allele was associated with an increased risk of chronic heart failure (OR $=1.38,95 \% \mathrm{CI}=1.09-1.75, p=0.007)$, especially in patients with hypertension (OR $=1.45,95 \% \mathrm{CI}=1.09-1.75, p=0.006)$ and coronary heart disease $(\mathrm{OR}=1.41,95 \%$ CI $=1.09-1.83, p=0.010)$ after adjustment for multiple cardiovascular risk factors. However, rs2306235 polymorphism was not associated with cardiovascular mortality in chronic heart failure $(p=0.875)$. CKIP-1 rs2306235 polymorphism may be a risk factor for chronic heart failure in a Chinese Han population.

\section{INTRODUCTION}

Chronic heart failure (CHF) is a complex clinical syndrome with a multifactorial etiology including genetic factors [1-6]. Nevertheless, the genetic background for sporadic $\mathrm{CHF}$ is poorly characterized yet, and identification of novel CHF susceptibility loci is helpful for personalized diagnosis and treatment of the disease.

The pleckstrin homology domain-containing protein casein kinase-2 interacting protein-1 (CKIP-1) was originally identified as a casein kinase- $2 \alpha$-subunit $(\mathrm{CK} 2 \alpha)$ interacting protein [7]. CKIP-1 protein contains a pleckstrin homology $(\mathrm{PH})$ domain and a leucine zipper (LZ) motif, which could mediate multiple interactions between CKIP-1 and numerous cellular proteins [8].
CKIP-1 plays scaffold roles in various signaling pathways [8], controlling cell growth [9-13], apoptosis [14, 15], differentiation [16], migration [17], morphology and cytoskeleton [18-20], and bone formation [21]. Moreover, CKIP-1 can inhibit pathological cardiac hypertrophy by promoting dephosphorylation of histone deacetylase 4 (HDAC4) through recruiting serine/threonine protein phosphatase 2A (PP2A) [22]. In mice model, cardiacspecific deficiency and overexpression of CKIP-1 exhibit hypersensitivity and resistance to pathological cardiac hypertrophy induced by pressure overload, respectively [22]. Also, CKIP-1 protein level was sharply reduced in the hypertrophied failing human hearts [22].

Pathological cardiac hypertrophy is an independent risk factor for CHF. Considering the crucial role of CKIP- 
1 in inhibiting pathological cardiac hypertrophy, CKIP1 may represent a potential candidate gene for $\mathrm{CHF}$. However, there is no report about association between CKIP-1 polymorphisms and risk of CHF yet. By using the 1000 genome data, we observed rs 2306235 polymorphism (Pro21Ala) in CKIP-1, and the 21st amino acid locates in the $\mathrm{PH}$ domain of CKIP-1. The PH domain is essential for localization of CKIP-1 in the plasma membrane (PM) and recruitment of multiple proteins to the PM [23]. To make clear the clinical relevance of CKIP-1 rs2306235 polymorphism, we herein performed a case-control study to investigate the association between CKIP-1 rs2306235 polymorphism and risk of $\mathrm{CHF}$ in a Chinese population.

\section{RESULTS}

\section{Baseline characteristics of study participants}

Baseline characteristics of the study participants were shown in Table 1. CHF and control participants were well matched in gender and age. The coefficients of variation, skewness, and kurtosis of healthy controls' age were $13.6 \%,-0.6$, and 0.6 , respectively. The coefficients of variation, skewness, and kurtosis of patients' age were $17.9 \%,-0.9$, and 0.8 , respectively. On the basis of selection criteria, controls had no hypertension, coronary heart disease, and diabetes. More participants in CHF group had dyslipidemia, smoking habit, higher levels of systolic and diastolic blood pressure, total cholesterol, triglyceride, low-density lipoprotein cholesterol, but lower level of high-density lipoprotein cholesterol. Etiologies of CHF consisted of $74.9 \%$ ischemic and $25.1 \%$ nonischemic heart failure.

\section{CKIP-1 rs2306235 polymorphism and risk of CHF}

The rs2306235 genotype distribution was shown in Table 2. Rs2306235 polymorphism was in HardyWeinberg equilibrium in both CHF patients and control population ( $p=0.896$ and 0.728 , respectively). The frequency of rs2306235 GC and GG genotype was significantly higher in CHF patients than in the controls (Table 2). Univariate analysis revealed that rs2306235 $\mathrm{G}$ allele (21Ala) was associated with increased risk of CHF $(\mathrm{OR}=1.36,95 \% \mathrm{CI}=1.07-1.71, p=0.010)$. After adjustment for age, gender, smoking status, and dyslipidemia, the association was still significant $(\mathrm{OR}=$ $1.38,95 \% \mathrm{CI}=1.09-1.75, p=0.007)$.

Considering that hypertension, coronary heart disease, and diabetes are important risk factor for heart failure, association analyses stratified by these comorbidities were further performed. Univariate analysis showed that rs2306235 G allele was associated with increased risk of CHF in patients with hypertension and coronary heart disease (hypertension: $\mathrm{OR}=1.40,95 \%$
$\mathrm{CI}=1.08-1.81, p=0.011$; coronary heart disease: $\mathrm{OR}=$ $1.37,95 \% \mathrm{CI}=1.07-1.76, p=0.014)$. Also, rs 2306235 $\mathrm{G}$ allele was associated with increased risk of $\mathrm{CHF}$ in nondiabetic patients $(\mathrm{OR}=1.35,95 \% \mathrm{CI}=1.05-1.73, p$ $=0.020)$. After adjusting for age, gender, smoking status, and dyslipidemia, the association was still significant (hypertension: $\mathrm{OR}=1.45,95 \% \mathrm{CI}=1.09-1.75, p=0.006$; coronary heart disease: $\mathrm{OR}=1.41,95 \% \mathrm{CI}=1.09-1.83$, $p=0.010$; diabetes: $\mathrm{OR}=1.59,95 \% \mathrm{CI}=1.08-2.35, p$ $=0.019$; nondiabetes: $\mathrm{OR}=1.35,95 \% \mathrm{CI}=1.05-1.73$, $p=0.021)$. However, rs2306235 polymorphism was not associated with risk of CHF in patients without hypertension and coronary heart disease (Table 2).

\section{CKIP-1 rs2306235 polymorphism and severity of CHF}

Echocardiographic examination was performed only in $839 \mathrm{CHF}$ patients. Comparisons of NYHA class, left ventricular ejection fraction (LVEF), and left ventricular end-diastolic diameter (LVEDD) among rs2306235 genotypes were presented in Table 3. No significant differences in NYHA class, LVEF, and LVEDD were observed among rs2306235 genotype groups ( $p=0.743$, 0.626 , and 0.652 , respectively).

\section{CKIP-1 rs2306235 polymorphism and prognosis of CHF}

A total of 140 patients were followed up for a median period of 38.7 months. No significant difference in cardiovascular mortality was observed between rs2306235 genotype groups (CC vs GC, $p=0.875$, Figure 1 ).

\section{DISCUSSION}

We firstly identified rs2306235 G allele associated with increased risk of CHF in the entire cohort. Stratified analyses demonstrated that the association was still significant in patients with hypertension and coronary heart disease regardless of diabetes mellitus. However, this polymorphism showed no association with severity and cardiovascular mortality in CHF patients.

Prolonged pressure stresses, including hypertension and myocardial infarction can lead to pathological cardiac hypertrophy and heart failure [24]. CKIP-1 can suppress pathological cardiac hypertrophy through promoting HDAC4 dephosphorylation by recruiting PP2A. [22]. CKIP-1 deficient mice develop spontaneous cardiac hypertrophy with aging and hypersensitivity to pressure overload-induced cardiac hypertrophy [22]. In contrast, myocardial CKIP-1 overexpression protects from pressure overload-induced cardiac hypertrophy [22]. Significant reduction of CKIP-1 protein level was also observed in the late phases of cardiac hypertrophy in mouse and human hearts [22]. Collectively, these data may suggest 
Table 1: Baseline characteristics of the study population

\begin{tabular}{|c|c|c|c|}
\hline Characteristics & CHF $(n=923)$ & Control $(n=1020)$ & $\boldsymbol{P}$ \\
\hline Male, n (\%) & $564(61.1)$ & $600(58.8)$ & 0.305 \\
\hline Age (years) & $61 \pm 11$ & $60 \pm 8$ & 0.122 \\
\hline $\mathrm{SBP}(\mathrm{mmHg})$ & $133.4 \pm 25.6$ & $113.6 \pm 9.5$ & $<0.001$ \\
\hline $\mathrm{DBP}(\mathrm{mmHg})$ & $79.4 \pm 14.4$ & $72.9 \pm 6.7$ & $<0.001$ \\
\hline $\mathrm{TC}(\mathrm{mmol} / \mathrm{L})$ & $4.6 \pm 1.0$ & $3.9 \pm 1.4$ & $<0.001$ \\
\hline $\mathrm{TG}(\mathrm{mmol} / \mathrm{L})$ & $1.8 \pm 1.8$ & $1.5 \pm 1.3$ & 0.001 \\
\hline $\mathrm{HDL}-\mathrm{C}(\mathrm{mmol} / \mathrm{L})$ & $1.3 \pm 1.0$ & $1.8 \pm 0.7$ & $<0.001$ \\
\hline LDL-C (mmol/L) & $2.4 \pm 0.9$ & $2.1 \pm 0.6$ & $<0.001$ \\
\hline Cigarette smoker, n (\%) & $313(33.9)$ & $255(25.0)$ & $<0.001$ \\
\hline Dyslipidemia, n (\%) & $267(28.9)$ & $196(19.2)$ & $<0.001$ \\
\hline Hypertension, n (\%) & $597(64.7)$ & $0(0)$ & $<0.001$ \\
\hline Coronary heart disease, $\mathrm{n}(\%)$ & $691(74.9)$ & $0(0)$ & $<0.001$ \\
\hline Diabetes mellitus (\%) & $233(25.2)$ & $0(0)$ & $<0.001$ \\
\hline Family history of heart failure, n (\%) & $3(0.3)$ & - & \\
\hline \multicolumn{4}{|l|}{ Etiology of heart failure } \\
\hline Ischemic, $\mathrm{n}(\%)$ & $691(74.9)$ & - & \\
\hline Nonischemic, n (\%) & $232(25.1)$ & - & \\
\hline \multicolumn{4}{|l|}{ Medications } \\
\hline Beta-blockers, n (\%) & $720(78.0)$ & - & \\
\hline ACE inhibitors, n (\%) & $474(51.3)$ & - & \\
\hline Angiotensin receptor blockers, n (\%) & $244(26.4)$ & - & \\
\hline Diuretics, n (\%) & $212(23.0)$ & - & \\
\hline Digoxin, n (\%) & $166(18.0)$ & - & \\
\hline Aldosterone antagonists, $\mathrm{n}(\%)$ & $151(16.3)$ & - & \\
\hline
\end{tabular}

SBP: systolic blood pressure, DBP: diastolic blood pressure, TC: total cholesterol, TG: triglyceride, HDL-C: high-density lipoprotein cholesterol, LDL-C: low-density lipoprotein cholesterol.

a inhibitory effect of CKIP-1 on heart failure caused by pathological cardiac hypertrophy.

Rs2306235 is a missense polymorphism (Pro 21 Ala) in CKIP-1 exon 2, which encodes the N-terminal $\mathrm{PH}$ domain of CKIP-1 [7]. This $\mathrm{PH}$ domain is required for interaction and recruitment of multiple proteins to the plasma membrane, where CKIP-1 localizes predominantly and perform most of its known functions [23]. Functional prediction of this polymorphism was performed using PROVEAN, SIFT, and PolyPhen-2. PROVEAN and SIFT assessment of the proline to alanine amino acid substitution predicted "neutral" and "tolerated", respectively; and PolyPhen-2 predicted this variant to be benign with a score of 0 (data not shown). However, its exact function deserves further investigation. Moreover, the MAF of rs2306235 polymorphism has ethnic difference. According to the 1000 Genomes Project, the MAF of rs2306235 ranges from 0.063 to 0.129 in East Asian population. However, the MAF is 0 in both American and African population. And also, rs2306235 is a rare polymorphism with MAF of 0.001 in the European population. Therefore, rs2306235 polymorphism may exhibit more significant association with CHF in East Asian population. 
Table 2: Association of CKIP-1 rs2306235 polymorphism with risk of CHF

\begin{tabular}{|c|c|c|c|c|c|c|c|}
\hline Models & Genotypes & $\begin{array}{l}\text { CHF, } \\
\text { n (\%) }\end{array}$ & $\begin{array}{c}\text { Control, } \\
\text { n (\%) }\end{array}$ & $\begin{array}{c}\text { Unadjusted OR } \\
(95 \% \mathrm{CI})\end{array}$ & $P$ & $\begin{array}{c}\text { Adjusted OR } \\
(95 \% \text { CI })\end{array}$ & $\boldsymbol{P}^{*}$ \\
\hline \multicolumn{8}{|c|}{ Entire cohort } \\
\hline \multirow[t]{3}{*}{ Additive } & $\mathrm{CC}$ & 736 (79.7) & $859(84.2)$ & 1.00 (reference) & & 1.00 (reference) & \\
\hline & $\mathrm{GC}$ & $176(19.1)$ & $155(15.2)$ & $1.33(1.05-1.68)$ & 0.020 & $1.36(1.07-1.73)$ & 0.013 \\
\hline & GG & $11(1.2)$ & $6(0.6)$ & $1.46(0.89-2.41)$ & 0.136 & $1.43(0.86-2.38)$ & 0.163 \\
\hline \multirow[t]{2}{*}{ Dominant } & $\mathrm{CC}$ & 736 (79.7) & $859(84.2)$ & 1.00 (reference) & & 1.00 (reference) & \\
\hline & $\mathrm{GC} / \mathrm{GG}$ & $187(20.3)$ & $161(15.8)$ & $1.36(1.07-1.71)$ & 0.010 & $1.38(1.09-1.75)$ & 0.007 \\
\hline \multicolumn{8}{|c|}{ Hypertension } \\
\hline \multirow[t]{3}{*}{ Additive } & $\mathrm{CC}$ & $473(79.2)$ & $859(84.2)$ & 1.00 (reference) & & 1.00 (reference) & \\
\hline & $\mathrm{GC}$ & $116(19.4)$ & $155(15.2)$ & $1.36(1.04-1.77)$ & 0.024 & $1.43(1.08-1.88)$ & 0.012 \\
\hline & GG & $8(1.3)$ & $6(0.6)$ & $1.56(0.91-2.65)$ & 0.103 & $1.47(0.85-2.55)$ & 0.166 \\
\hline \multirow[t]{2}{*}{ Dominant } & $\mathrm{CC}$ & $473(79.2)$ & 859 (84.2) & 1.00 (reference) & & 1.00 (reference) & \\
\hline & $\mathrm{GC} / \mathrm{GG}$ & $124(20.8)$ & $161(15.8)$ & $1.40(1.08-1.81)$ & 0.011 & $1.45(1.11-1.90)$ & 0.006 \\
\hline \multicolumn{8}{|c|}{ Nonhypertension } \\
\hline \multirow[t]{3}{*}{ Additive } & $\mathrm{CC}$ & $263(80.7)$ & $859(84.2)$ & 1.00 (reference) & & 1.00 (reference) & \\
\hline & $\mathrm{GC}$ & $60(18.4)$ & 155 (15.2) & $1.26(0.91-1.76)$ & 0.162 & $1.25(0.89-1.75)$ & 0.199 \\
\hline & GG & $3(0.9)$ & $6(0.6)$ & $1.28(0.64-2.56)$ & 0.490 & $1.27(0.62-2.61)$ & 0.522 \\
\hline \multirow[t]{2}{*}{ Dominant } & $\mathrm{CC}$ & $263(80.7)$ & $859(84.2)$ & 1.00 (reference) & & 1.00 (reference) & \\
\hline & $\mathrm{GC} / \mathrm{GG}$ & $63(19.3)$ & $161(15.8)$ & $1.28(0.93-1.76)$ & 0.136 & $1.26(0.90-1.76)$ & 0.174 \\
\hline \multicolumn{8}{|l|}{ CHD } \\
\hline \multirow[t]{3}{*}{ Additive } & $\mathrm{CC}$ & $550(79.6)$ & $859(84.2)$ & 1.00 (reference) & & 1.00 (reference) & \\
\hline & $\mathrm{GC}$ & 133 (19.2) & $155(15.2)$ & $1.34(1.04-1.73)$ & 0.025 & $1.39(1.07-1.82)$ & 0.015 \\
\hline & GG & $8(1.2)$ & $6(0.6)$ & $1.44(0.85-2.46)$ & 0.177 & $1.37(0.79-2.38)$ & 0.267 \\
\hline \multirow[t]{2}{*}{ Dominant } & $\mathrm{CC}$ & $550(79.6)$ & $859(84.2)$ & 1.00 (reference) & & 1.00 (reference) & \\
\hline & $\mathrm{GC} / \mathrm{GG}$ & $141(20.4)$ & $161(15.8)$ & $1.37(1.07-1.76)$ & 0.014 & $1.41(1.09-1.83)$ & 0.010 \\
\hline \multicolumn{8}{|l|}{ Non-CHD } \\
\hline \multirow[t]{3}{*}{ Additive } & $\mathrm{CC}$ & $186(80.2)$ & $859(84.2)$ & 1.00 (reference) & & 1.00 (reference) & \\
\hline & $\mathrm{GC}$ & $43(18.5)$ & $155(15.2)$ & $1.28(0.88-1.86)$ & 0.193 & $1.24(0.84-1.82)$ & 0.280 \\
\hline & GG & $3(1.3)$ & $6(0.6)$ & $1.52(0.76-3.05)$ & 0.240 & $1.81(0.89-3.69)$ & 0.103 \\
\hline \multirow[t]{2}{*}{ Dominant } & $\mathrm{CC}$ & $186(80.2)$ & $859(84.2)$ & 1.00 (reference) & & 1.00 (reference) & \\
\hline & $\mathrm{GC} / \mathrm{GG}$ & $46(19.8)$ & $161(15.8)$ & $1.32(0.92-1.90)$ & 0.135 & $1.29(0.89-1.88)$ & 0.180 \\
\hline \multicolumn{8}{|l|}{ Diabetes } \\
\hline \multirow[t]{3}{*}{ Additive } & $\mathrm{CC}$ & $185(79.4)$ & $859(84.2)$ & 1.00 (reference) & & 1.00 (reference) & \\
\hline & $\mathrm{GC}$ & $47(20.2)$ & $155(15.2)$ & $1.41(0.98-2.02)$ & 0.065 & $1.65(1.12-2.45)$ & 0.012 \\
\hline & GG & $1(0.4)$ & $6(0.6)$ & $0.88(0.30-2.54)$ & 0.813 & $0.72(0.23-2.21)$ & 0.561 \\
\hline
\end{tabular}

(Continued) 


\begin{tabular}{|c|c|c|c|c|c|c|c|}
\hline Models & Genotypes & $\begin{array}{l}\text { CHF, } \\
\text { n (\%) }\end{array}$ & $\begin{array}{c}\text { Control, } \\
\text { n (\%) }\end{array}$ & $\begin{array}{c}\text { Unadjusted OR } \\
(95 \% \mathrm{CI})\end{array}$ & $P$ & $\begin{array}{l}\text { Adjusted OR } \\
(95 \% \text { CI) }\end{array}$ & $\boldsymbol{P}^{*}$ \\
\hline \multirow[t]{2}{*}{ Dominant } & $\mathrm{CC}$ & $185(79.4)$ & $859(84.2)$ & 1.00 (reference) & & 1.00 (reference) & \\
\hline & $\mathrm{GC} / \mathrm{GG}$ & $48(20.6)$ & $161(15.8)$ & $1.38(0.97-1.98)$ & 0.076 & $1.59(1.08-2.35)$ & 0.019 \\
\hline \multicolumn{8}{|c|}{ Nondiabetes } \\
\hline \multirow[t]{3}{*}{ Additive } & $\mathrm{CC}$ & $551(79.9)$ & $859(84.2)$ & 1.00 (reference) & & 1.00 (reference) & \\
\hline & $\mathrm{GC}$ & $129(18.7)$ & $155(15.2)$ & $1.30(1.00-1.68)$ & 0.047 & $1.30(1.00-1.68)$ & 0.047 \\
\hline & GG & $10(1.4)$ & $6(0.6)$ & $1.61(0.97-2.68)$ & 0.066 & $1.62(0.97-2.70)$ & 0.065 \\
\hline \multirow[t]{2}{*}{ Dominant } & $\mathrm{CC}$ & $551(79.9)$ & 859 (84.2) & 1.00 (reference) & & 1.00 (reference) & \\
\hline & $\mathrm{GC} / \mathrm{GG}$ & $139(21.4)$ & $161(15.8)$ & $1.35(1.05-1.73)$ & 0.020 & $1.35(1.05-1.73)$ & 0.021 \\
\hline
\end{tabular}

OR: odd ratio; CI: confidence interval. CHD: Coronary heart disease. *Adjusted for age, gender, smoking status, and dyslipidemia.

Table 3: Association of CKIP-1 rs2306235 polymorphism with severity of CHF

\begin{tabular}{llccc}
\hline Variables & CC $(\mathbf{n}=\mathbf{7 3 6})$ & GC (176) & GG $(\mathbf{n}=\mathbf{1 1})$ & $\boldsymbol{P}$ \\
\hline NYHA class & & & & 0.743 \\
II, n (\%) & $256(34.8)$ & $61(34.7)$ & $3(27.3)$ & \\
III, n (\%) & $273(37.1)$ & $70(39.8)$ & $6(54.5)$ & \\
IV, n (\%) & $207(28.1)$ & $45(25.6)$ & $2(18.2)$ & \\
LVEF (\%) & $38.2 \pm 9.2$ & $37.5 \pm 9.2$ & $37.6 \pm 10.4$ & 0.626 \\
LVEDD (mm) & $61.1 \pm 7.6$ & $61.7 \pm 6.7$ & $61.3 \pm 8.6$ & 0.652 \\
\hline
\end{tabular}

NYHA: New York Heart Association, LVEF: left ventricular ejection fraction, LVEDD: left ventricular end-diastolic diameter. "Based on 839 patients with chronic heart failure.

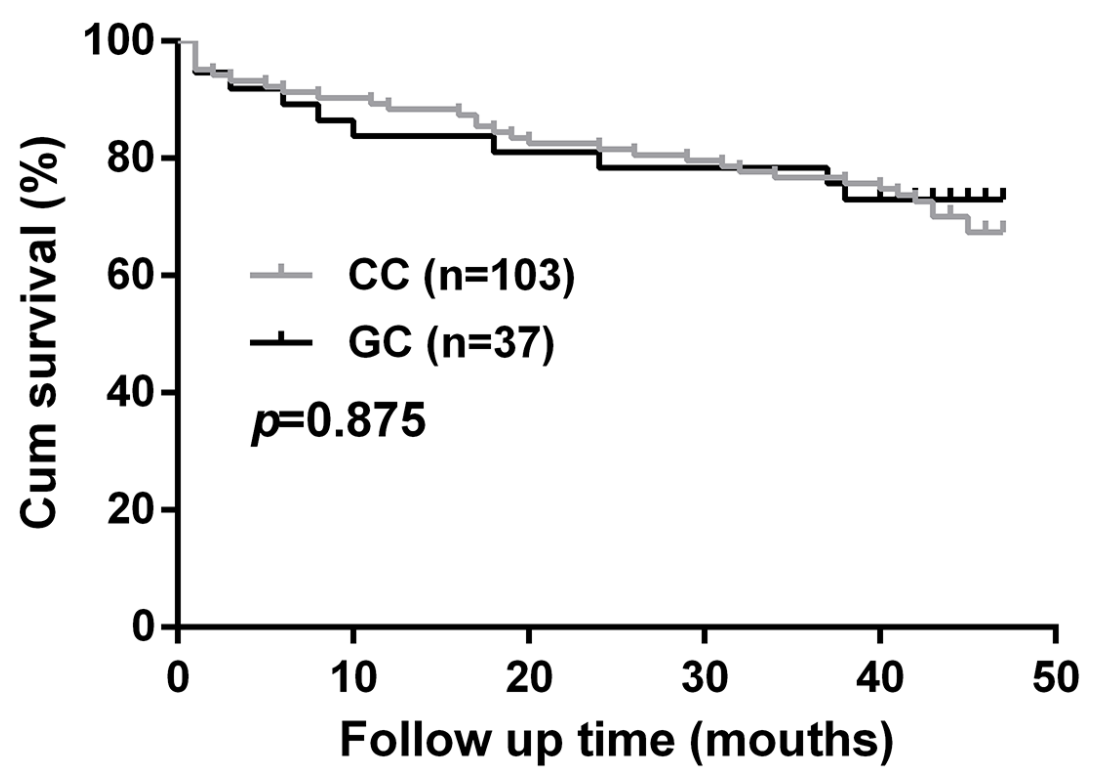

Figure 1: Association of CKIP-1 rs2306235 polymorphism with cardiovascular mortality in chronic heart failure patients. 
Considering that hypertension, coronary heart disease, and diabetes are important risk factors for heart failure [25], stratified analysis was further performed. Stratified analysis showed that rs 2306235 polymorphism was significantly associated with risk of CHF in patients with hypertension and coronary heart disease. This association was also evident in both diabetic and nondiabetic heart failure, which indicated that rs 2306235 polymorphism modify risk of CHF independent of diabetes. Left ventricular hypertrophy, the most visible manifestation of target organ damage in hypertension, eventually predisposes to heart failure [26]. Moreover, coronary heart disease also has a higher prevalence of left ventricular hypertrophy [27]. Given the crucial role of CKIP-1 in inhibiting cardiac hypertrophy, CKIP-1 polymorphism may be a potential risk factor for $\mathrm{CHF}$ in patients with hypertension and coronary heart disease.

Several limitations of this study deserve consideration. First, we only enrolled Han Chinese participants with relatively limited sample size. As MAF of rs2306235 varies among different ethnicities, whether our results are generalized to other ethnicity still needs to be clarified. Second, only rs 2306235 polymorphism was investigated in the present study, other potentially functional polymorphisms in CKIP-1 should been evaluated for their association with CHF. In addition, fewer patients were followed up in a relatively short period of time. Further study with larger patients and long term follow up is needed. Finally, functional assessment of rs2306235 polymorphism was not performed. Therefore, further investigations are necessary to clarify the exact relationship between this variant and heart failure.

In conclusion, we firstly revealed the association of CKIP-1 rs2306235 polymorphism with an increased risk of CHF in Chinese Han populations. Further investigations in larger cohorts may be required to verify our findings. More comprehensive survey and functional experiments are also needed to illuminate the exact mechanism behind our findings.

\section{MATERIALS AND METHODS}

\section{Study participants}

A total of 923 patients with CHF were recruited between November 2011 and December 2014 from Xiangya Hospital, Central South University. The eligibility criteria were described previously [5]. Patients with heart failure were eligible if they were aged 20-80 years and had chronic and stable heart failure symptoms, as demonstrated by New York Heart Association functional class II-IV, for more than three months prior to study initiation. The exclusion criteria were tumors or malignant disease, severe hepatic or renal dysfunctions, and pregnancy. The etiology of heart failure included ischemic heart disease and nonischemic cardiomyopathy. Ischemic heart disease was defined by satisfying one of the following conditions: $\geq 50 \%$ luminal stenosis of at least one major coronary artery, history of myocardial infarction $\geq$ three months before enrolment, history of coronary artery bypass graft, and coronary stent implantation. Patients were contacted by a questionnaire during regular outpatient clinics or by a structured telephone interview. Data concerning cardiovascular mortality during the follow-up period were collected.

A group of 1020 age- and gender-matched healthy controls were also enrolled in physical examination center of the same hospital. The subjects were apparently healthy as assessed by physical examination, serum biochemical testing, and electrocardiogram. Hypertension was defined as participants with a systolic blood pressure (SBP) $\geq$ $140 \mathrm{mmHg}$ and/or a diastolic blood pressure (DBP) $\geq 90$ $\mathrm{mmHg}$ or those who received at least one antihypertensive medication. Coronary heart disease (CHD) was defined as luminal stenosis $\geq 50 \%$ in at least one major coronary artery branch or myocardial infarction. Diabetic mellitus was diagnosed as a fasting plasma glucose $\geq 7.0 \mathrm{mmol} / \mathrm{L}$ or under diabetes medication. The healthy controls had no histories or symptoms of hypertension, CHD, diabetes mellitus, or any other cardiovascular diseases.

All subjects were Han Chinese origin as ascertained by their resident identity card. The study protocol was approved by the ethic committee of School of Pharmaceutical Sciences, Central South University and registered in Chinese Clinical Trial Registry (registration number: ChiCTR-RCC-12002817). Informed consent was obtained from each participants prior to enrollment.

\section{Polymorphism selection and genotyping}

Based on the CHB population (Han Chinese in Beijing, China) of 1000 Genomes project (http:// browser.1000genomes.org), a total of seven tag polymorphisms with minor allele frequency (MAF) $>0.05$ were identified using Haploview 4.2 software. Among them, only rs2306235 polymorphism is located in CKIP-1 exon. This polymorphism results in replacement of proline by alanine at the 21 amino acid (Pro21Ala). This amino acid is located in the CKIP-1 PH domain [7], which is required for mediating multiple interactions between CKIP-1 and numerous cellular proteins [8]. Therefore, rs2306235 polymorphism was selected in our study.

Venous blood samples were collected into EDTA tube and stored at $-20^{\circ} \mathrm{C}$. Genomic DNA of each subject was extracted from peripheral blood leukocytes using the standard phenol/chloroform protocol. CKIP1 rs2306235 polymorphism was genotyped by PCRrestriction fragment length polymorphism. The target fragment of $425 \mathrm{bp}$ was amplified using primers 5 '-tgaaaacetttccgaagtgg-3' and 5' -accactgaacttgcctttgg-3' (forward/reverse). Five microliters of PCR products was digested with Pst I restriction enzyme (Thermo Fisher 
Scientific, Waltham, MA, USA) overnight at $37^{\circ} \mathrm{C}$. The digested PCR products were then analyzed on an agarose gel followed by ethidium bromide staining. Additionally, a random selection of $5 \%$ of the samples was also genotyped by Sanger sequencing with the ABI PRISM 3730XL DNA sequencer (Applied Biosystems, Foster City, CA, USA) and the genotyping were confirmed in $100 \%$.

\section{Statistical analysis}

Continuous values were expressed as mean $\pm \mathrm{SD}$ and categorical variables as numbers and percentages. Patient characteristics were compared using Chi-square test for categorical variables and independent sample $t$ test or one way analysis of variance for continuous variables. Hardy-Weinberg equilibrium of genotypic distribution was evaluated using a Chi-square test. The association between CKIP-1 polymorphism and the risk of CHF was estimated by unconditional logistic regression analysis adjusting for multiple cardiovascular risk factors. The effect of CKIP-1 polymorphism on disease survival was estimated using Kaplan-Meier curve and Cox proportional hazards regression model. The statistical analysis was performed with SPSS software (version 13.0, SPSS Inc., Chicago, IL, USA). A two-sided $p$ value $<0.05$ was considered to be statistically significant.

\section{Abbreviations}

CHF, chronic heart failure; CKIP-1, casein kinase-2 interacting protein-1; $\mathrm{PH}$ domain, pleckstrin homology domain; HDAC4, dephosphorylation of histone deacetylase 4; SBP, systolic blood pressure; DBP, diastolic blood pressure; TC, total cholesterol; LDL-C, low-density lipoprotein cholesterol; HDL-C, high-density lipoprotein cholesterol; MAF, minor allele frequency; CHD, coronary heart disease; LVEF, left ventricular ejection fraction; LVEDD, left ventricular end-diastolic diameter.

\section{Authors' contributions}

Xiao-Ping Chen and Mu-Peng Li designed the study; Mu-Peng Li, Yan-Jiao Zhang, and Xiao-Lei Hu performed the genotyping; Mu-Peng Li, Ji-Peng Zhou, Yong-Long Yang, Li-Ming Peng, and Hong Qi collected blood samples and clinical data; Mu-Peng Li drafted the manuscript; Xiao-Ping Chen and Tian-Lun Yang revised the manuscript critically. All authors agreed on the final version of the manuscript.

\section{ACKNOWLEDGMENTS}

The authors are grateful to physicians and nursing staff of the Ward 47, Department of Cardiovascular Medicine, Xiangya Hospital, Central South University.
Appreciation is also owned to all the subjects for their participation and collaboration.

\section{CONFLICTS OF INTEREST}

The authors have no conflicts of interest to declare.

\section{FUNDING}

This project was supported by National Science and Technology Major Project (2013ZX09509107), National Natural Science Foundation of China (81373489, 81422052, and 81403018), and Fundamental Research Funds for the Central Universities of Central South University (2014zzts073).

\section{REFERENCES}

1. Roger VL. Epidemiology of heart failure. Circ Res. 2013; 113: 646-59. doi: 10.1161/CIRCRESAHA.113.300268.

2. Lopes LR, Elliott PM. Genetics of heart failure. Biochim Biophys Acta. 2013; 1832: 2451-61. doi: 10.1016/j. bbadis.2012.12.012.

3. Zhai YJ, Liu P, He HR, Zheng XW, Wang Y, Yang QT, Dong YL, Lu J. The association of ADORA2A and ADORA2B polymorphisms with the risk and severity of chronic heart failure: a case-control study of a northern Chinese population. Int J Mol Sci. 2015; 16: 2732-46. doi: 10.3390/ijms 16022732 .

4. He GH, Cai WK, Meng JR, Ma X, Zhang F, Lu J, Xu GL. Relation of polymorphism of the histidine decarboxylase gene to chronic heart failure in Han Chinese. Am J Cardiol. 2015; 115: 1555-62. doi: 10.1016/j.amjcard.2015.02.062.

5. Hu XL, Zhou JP, Kuang DB, Qi H, Peng LM, Yang TL, Li X, Zhang W, Zhou HH, Chen XP. Considerable impacts of AGXT2 V140I polymorphism on chronic heart failure in the Chinese population. Atherosclerosis. 2016; 251: 255-62. doi: 10.1016/j.atherosclerosis.2016.07.006.

6. Sandip C, Tan L, Huang J, Li Q, Ni L, Cianflone K, Wang DW. Common variants in IL-17A/IL-17RA axis contribute to predisposition to and progression of congestive heart failure. Medicine (Baltimore). 2016; 95: e4105. doi: 10.1097/MD.0000000000004105.

7. Bosc DG, Graham KC, Saulnier RB, Zhang C, Prober D, Gietz RD, Litchfield DW. Identification and characterization of CKIP-1, a novel pleckstrin homology domain-containing protein that interacts with protein kinase CK2. J Biol Chem. 2000; 275: 14295-306. doi: 10.1074/jbc.275.19.14295.

8. Nie J, Liu L, He F, Fu X, Han W, Zhang L. CKIP-1: a scaffold protein and potential therapeutic target integrating multiple signaling pathways and physiological functions. Ageing Res Rev. 2013; 12: 276-81. doi: 10.1016/j. arr.2012.07.002. 
9. Tokuda E, Fujita N, Oh-hara T, Sato S, Kurata A, Katayama $\mathrm{R}$, Itoh $\mathrm{T}$, Takenawa $\mathrm{T}$, Miyazono $\mathrm{K}$, Tsuruo $\mathrm{T}$. Casein kinase 2-interacting protein-1, a novel Akt pleckstrin homology domain-interacting protein, down-regulates $\mathrm{PI} 3 \mathrm{~K} / \mathrm{Akt}$ signaling and suppresses tumor growth in vivo. Cancer Res. 2007; 67: 9666-76. doi: 10.1158/0008-5472. can-07-1050.

10. Nie J, Liu L, Xing G, Zhang M, Wei R, Guo M, Li X, Xie P, Li L, He F, Han W, Zhang L. CKIP-1 acts as a colonic tumor suppressor by repressing oncogenic Smurfl synthesis and promoting Smurf1 autodegradation. Oncogene. 2014; 33: 3677-87. doi: 10.1038/onc.2013.340.

11. Li D, Zhu H, Liang C, Li W, Xing G, Ma L, Ding L, Zhang $\mathrm{Y}, \mathrm{He}$ F, Zhang L. CKIP-1 suppresses the adipogenesis of mesenchymal stem cells by enhancing HDAC1-associated repression of C/EBPalpha. J Mol Cell Biol. 2014; 6: 36879. doi: $10.1093 / \mathrm{jmcb} / \mathrm{mju} 034$.

12. Zhang L, Wang Y, Xiao F, Wang S, Xing G, Li Y, Yin X, Lu K, Wei R, Fan J, Chen Y, Li T, Xie P, et al. CKIP-1 regulates macrophage proliferation by inhibiting TRAF6mediated Akt activation. Cell Res. 2014; 24: 742-61. doi: 10.1038/cr.2014.53.

13. Zhu X, Ouyang Y, Zhong F, Wang Q, Ding L, Zhang P, Chen L, Liu H, He S. Silencing of CKIP-1 promotes tumor proliferation and cell adhesion-mediated drug resistance via regulating AKT activity in non-Hodgkin's lymphoma. Oncol Rep. 2017; 37:622-30. doi: 10.3892/or.2016.5233.

14. Zhang L, Xing G, Tie Y, Tang Y, Tian C, Li L, Sun L, Wei H, Zhu Y, He F. Role for the pleckstrin homology domain-containing protein CKIP-1 in AP-1 regulation and apoptosis. Embo j. 2005; 24: 766-78. doi: 10.1038/ sj.emboj.7600532.

15. Juhasz K, Zvara A, Lipp AM, Nimmervoll B, Sonnleitner A, Balogi Z, Duda E. Casein kinase 2-interacting protein-1, an inflammatory signaling molecule interferes with TNF reverse signaling in human model cells. Immunol Lett. 2013; 152: 55-64. doi: 10.1016/j.imlet.2013.04.001.

16. Safi A, Vandromme M, Caussanel S, Valdacci L, Baas D, Vidal M, Brun G, Schaeffer L, Goillot E. Role for the pleckstrin homology domain-containing protein CKIP-1 in phosphatidylinositol 3-kinase-regulated muscle differentiation. Mol Cell Biol. 2004; 24: 1245-55. doi: 10.1128/MCB.24.3.1245-1255.2004.

17. Zhang L, Xia X, Zhang M, Wang Y, Xing G, Yin X, Song L, He F, Zhang L. Integrated analysis of genomics and proteomics reveals that CKIP-1 is a novel macrophage migration regulator. Biochem Biophys Res Commun. 2013; 436: 382-7. doi: 10.1016/j.bbrc.2013.05.109.

18. Canton DA, Olsten ME, Kim K, Doherty-Kirby A, Lajoie G, Cooper JA, Litchfield DW. The pleckstrin homology domain-containing protein CKIP-1 is involved in regulation of cell morphology and the actin cytoskeleton and interaction with actin capping protein. Mol Cell Biol. 2005; 25: 3519-34. doi: 10.1128/ mcb.25.9.3519-3534.2005.

19. Canton DA, Olsten ME, Niederstrasser H, Cooper JA, Litchfield DW. The role of CKIP-1 in cell morphology depends on its interaction with actin-capping protein. J Biol Chem. 2006; 281: 36347-59. doi: 10.1074/jbc. M607595200.

20. Baas D, Caussanel-Boude S, Guiraud A, Calhabeu F, Delaune E, Pilot F, Chopin E, Machuca-Gayet I, Vernay A, Bertrand S, Rual JF, Jurdic P, Hill DE, et al. CKIP-1 regulates mammalian and zebrafish myoblast fusion. J Cell Sci. 2012; 125: 3790-800. doi: 10.1242/jcs. 101048.

21. Lu K, Yin X, Weng T, Xi S, Li L, Xing G, Cheng X, Yang X, Zhang L, He F. Targeting WW domains linker of HECTtype ubiquitin ligase Smurf1 for activation by CKIP-1. Nat Cell Biol. 2008; 10: 994-1002. doi: 10.1038/ncb1760.

22. Ling S, Sun Q, Li Y, Zhang L, Zhang P, Wang X, Tian C, Li Q, Song J, Liu H, Kan G, Cao H, Huang Z, et al. CKIP-1 inhibits cardiac hypertrophy by regulating class II histone deacetylase phosphorylation through recruiting PP2A. Circulation. 2012; 126: 3028-40. doi: 10.1161/ circulationaha.112.102780.

23. Xi S, Tie Y, Lu K, Zhang M, Yin X, Chen J, Xing G, Tian C, Zheng X, He F, Zhang L. N-terminal PH domain and C-terminal auto-inhibitory region of CKIP-1 coordinate to determine its nucleus-plasma membrane shuttling. FEBS Lett. 2010; 584: 1223-30. doi: 10.1016/j. febslet.2010.02.036.

24. Tham YK, Bernardo BC, Ooi JY, Weeks KL, McMullen JR. Pathophysiology of cardiac hypertrophy and heart failure: signaling pathways and novel therapeutic targets. Arch Toxicol. 2015; 89: 1401-38. doi: 10.1007/ s00204-015-1477-x.

25. Yancy CW, Jessup M, Bozkurt B, Butler J, Casey DE Jr, Drazner MH, Fonarow GC, Geraci SA, Horwich T, Januzzi JL, Johnson MR, Kasper EK, Levy WC, et al. 2013 ACCF/ AHA guideline for the management of heart failure: a report of the American College of Cardiology Foundation/ American Heart Association Task Force on Practice Guidelines. J Am Coll Cardiol. 2013; 62: e147-239. doi: 10.1016/j.jacc.2013.05.019.

26. Nadruz W. Myocardial remodeling in hypertension. J Hum Hypertens. 2015; 29:1-6. doi: 10.1038/jhh.2014.36.

27. Misumida N, Kobayashi A, Saeed M, Fox JT, Kanei Y. Electrocardiographic Left Ventricular Hypertrophy as a Predictor for Nonsignificant Coronary Artery Disease in Patients With Non-ST-Segment Elevation Myocardial Infarction. Angiology. 2016; 67:27-33. doi: 10.1177/0003319715574803. 